\title{
Neonatal pulmonary hypoplasia after prolonged leakage of amniotic fluid
}

\author{
M. PERLMAN, J. WILLIAMS, and M. HIRSCH \\ From the Neonatal Unit and Radiology Department, Soroka Medical Centre, Beer Sheva, Israel
}

\begin{abstract}
Perlman, M., Williams, J., and Hirsch, M. (1976). Archives of Disease in Childhood, 51, 349. Neonatal pulmonary hypoplasia after prolonged leakage of amniotic fluid. The clinical, radiological, and pathological features of the 'oligohydramnios tetrad' (Potter's facies, limb malpositions, pulmonary hypoplasia, and growth retardation) resulting from chronic amniotic fluid leakage are described in 2 infants who died of respiratory failure within 12 hours of delivery. A third infant with a partial form of the syndrome had prolonged respiratory symptoms and survived the neonatal period: the course of the disease and the radiological findings were compatible with a hypothetical diagnosis of partial pulmonary hypoplasia. Pulmonary hypoplasia should be recognized as a cause of chronic respiratory symptoms in viable infants.
\end{abstract}

Pulmonary hypoplasia has been recognized by pathologists in infants born after pregnancies complicat $\epsilon$ by oligehydramnios due to prolonged leakage of amniotic fluid, and dying within hours of birth (Blanc, Apperson, and McNally, 1962; Bain, Smith, and Gauld, 1964; Kohler, Peel, and Hoar, 1970). We describe here the clinical, radiological, and pathological aspects of this condition in 2 infants and report an additional patient with features which are interpr sted as due to a partial, norlethal form of the syndrome.

\section{Case reports}

Case 1. A female infant was born to a 23-year-old gravida 1, para 1 mother after 33 weeks' gestation. The pregnancy was uncomplicated until the 23 rd week when the appearance of a watery vaginal discharge prompted admission. The mother was kept resting in hospital owing to the persistence of the watery discharge. The height of the uterine fundus was consistently smaller than the anticipated level by 2 to 4 weeks. The mother remained afebrile and 10.5 weeks after admission labour began spontaneously. Although amniotic fluid was noted to be scanty during parturition, the breech delivery was uncomplicated. The infant did not attempt to breathe but after positive pressure ventilation respiration was established. The Apgar score was 1 at 1 minute and 6 at 5 minutes, and the birthweight was $1800 \mathrm{~g}$. The placenta showed evidence of partial abruption.

Received 27 August 1975.
On examination shortly after birth the infant was deeply cyanosed, hypotonic, and lethargic. The respiratory rate was $40 / \mathrm{min}$ and there were periods of slow, deep breathing interspersed with periods of rapid shallow breathing. Severe inspiratory retractions were present. Secretions from the mouth were copious, viscid, and bubbly. Micrognathia and neck webbing were present. The auricles were large and low set, and prominent folds ran downwards and outwards from the inner canthus of each eye. The lower limbs were hyperflexed.

$\mathrm{Hb} 23 \mathrm{~g} / \mathrm{dl}$; platelet count was $66000 / \mathrm{cm}^{3}$. Blood glucose and electrolyte values were normal. Chest $x$-ray one hour after birth showed almost complete opacification of the left lung with fine streaks of air in the major bronchi only; the right lung was minimally aerated. Respiration continued to be periodic but failed 6 hours after birth. There was no response to resuscitation and the infant died.

At necropsy pathological findings were limited to the lungs. The lung weight : body weight ratio of $0 \cdot 10$ was reduced (normal 0.22 mean $\pm 0.02 \mathrm{SD}$; Reale and Esterly, 1973) and histological findings of retarded alveolar development were consistent with the diagnosis of pulmonary hypoplasia (Potter, 1961). The radial alveolar count of 2.0 (normal 3.2 mean \pm 2 SEM; Emery and Mithal, 1960) confirmed quantitatively the lack of alveoli.

Case 2. A male infant was born to a para 2 mother after 34 weeks' gestation. Four episodes of vaginal bleeding occurred between 16 and 25 weeks' gestation. The last episode was accompanied by a copious watery vaginal discharge, persisting until delivery and necessita- 
ting the use of about 20 menstrual pads daily. During the last 9 weeks of her pregnancy the mother was kept in bed. Placentography at 31 weeks showed a placenta in two parts with the intermediate part overlaying the cervix.

Breech delivery occurred spontaneously after 34 weeks' gestation, the Apgar score was 6 and 9 at 1 and 5 minutes, respectively. The placenta was membranous. Birthweight was $1740 \mathrm{~g}$. The facies was abnormal: nasal bridge broad and tip depressed; marked infraorbital skin creases; small chin with skin crease; large low-set ears; short neck with redundant skin folds (Fig. 1). In addition, the hands were large and 'meaty', and there were mild flexion deformities of the hips, knees, and ankles.

Tachypnoea and retractions were present from birth, breath sounds were faint, and repeated apnoeic attacks occurred. At 11 hours endotracheal intubation was performed, difficulty was experienced in inflating the lungs and clinical signs of bilateral pneumothoraces and subcutaneous emphysema of the neck appeared. In spite of pleural drainage and continued artificial ventilation the infant died.

At necropsy the combined weight of the lungs was $28 \mathrm{~g}$ giving a lung weight: body weight ratio of $0 \cdot 16$. The lungs were dark and appeared to be distended with fluid. Microscopy showed a disproportionate representation of

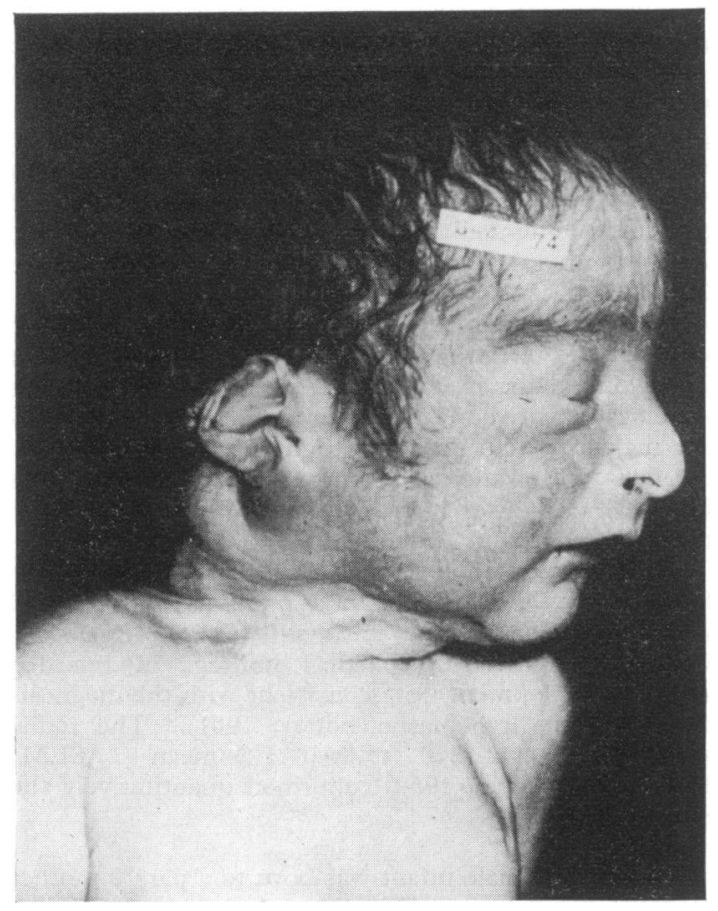

FIG. 1.-Case 2 (photographed post mortem). Facies showing depressed tip of nose, flattened low-set ears, small mandible with skin crease, and redundant skin folds of neck. bronchi in relation to alveoli. Interstitial emphysema and intra-alveolar haemorrhage was also detected. The mean radial alveolar count was $2 \cdot 3$ (normal $3 \cdot 2$ mean \pm 0.2 SEM). The only extrapulmonary pathology found was a small tentorial tear.

Case 3. A female infant was born to a gravida 12, para 9 mother aged 30 years after 33 weeks' gestation. 8 previous children were alive and well and had birthweights between 3500 and $3800 \mathrm{~g}$. The mother was in good health and the present pregnancy was uncomplicated until the 31 st week.

Sixteen days before admission the mother neticed a watery vaginal discharge. She was referred to hospital but owing to the absence of positive findings at examination she was discharged home with instructions to return in case of renewed symptoms. The watery discharge recurred on the same day but despite its persistence the mother did not seek further treatment and continued her usual way of life. She reported later that the watery discharge was copious and continued until the onset of labour pains 11 hours before admission to hospital. The infant was delivered 5 minutes after admission. According to the mother her labour was 'dry'. The placenta and membranes were described as complete. The Apgar score was 5 at 1 minute and 8 at 5 minutes; birthweight was $1720 \mathrm{~g}$ and head circumference $29 \mathrm{~cm}$.

On examination the infant had central cyanosis corrected by added oxygen, moderately severe subcostal retractions and a respiratory rate of $86 / \mathrm{min}$. Breath sounds were diminished and no added sounds were heard. The facies was abnormal: depressed tip of nose, micrognathia, and large low-set ears; there were also web neck, small thorax, 'fleshy' hands, and bilateral calcaneovalgus deformity of the feet. The limbs were hyperflexed but neonatal reflexes were appropriate for gestational age. Chest $x$-ray at age of 2 hours showed an unduly small thoracic cage and minimal aeration of the peripheral lung fields (Fig. 2a). Right radial artery blood while breathing room air gave $\mathrm{Po}_{2} 31 \mathrm{mmHg}$, $\mathrm{PCO}_{2} 76 \mathrm{mmHg}$, and $\mathrm{pH} \mathrm{7.06}$.

The infant was treated with the usual supportive measures and penicillin and kanamycin. The course was characterized by continued tachypnoea, increasing breath sounds, and a progressively reduced requirement for added oxygen. At the age of 2 days right radial artery blood gases while breathing air gave $\mathrm{Po}_{2} 38$ $\mathrm{mmHg}, \mathrm{PCO}_{2} 47 \mathrm{mmHg}$, and $\mathrm{pH} \mathrm{7 \cdot 25}$. On the third day chest $x$-ray showed an obvious increase in the transverse diameter of the bony thorax and improved aeration of the lungs (Fig. 2b). At one week the electrocardiogram was normal. The karyotype was that of a normal female.

The infant was discharged to a recovery nursery in andther city at the age of 11 days. At that time the respiratory rate was $68 / \mathrm{min}$. Right radial artery blood gave $\mathrm{Po}_{2} 49 \mathrm{mmHg}, \mathrm{PcO}_{2} 44 \mathrm{mmHg}$, and $p \mathrm{H} \mathrm{7.36}$. She was seen by one of us, and continued to have tachypnoea without retractions. At the age of 3 weeks the respiratory rate was $62 / \mathrm{min}$ and at 6 weeks $56 / \mathrm{min}$. Inter- 


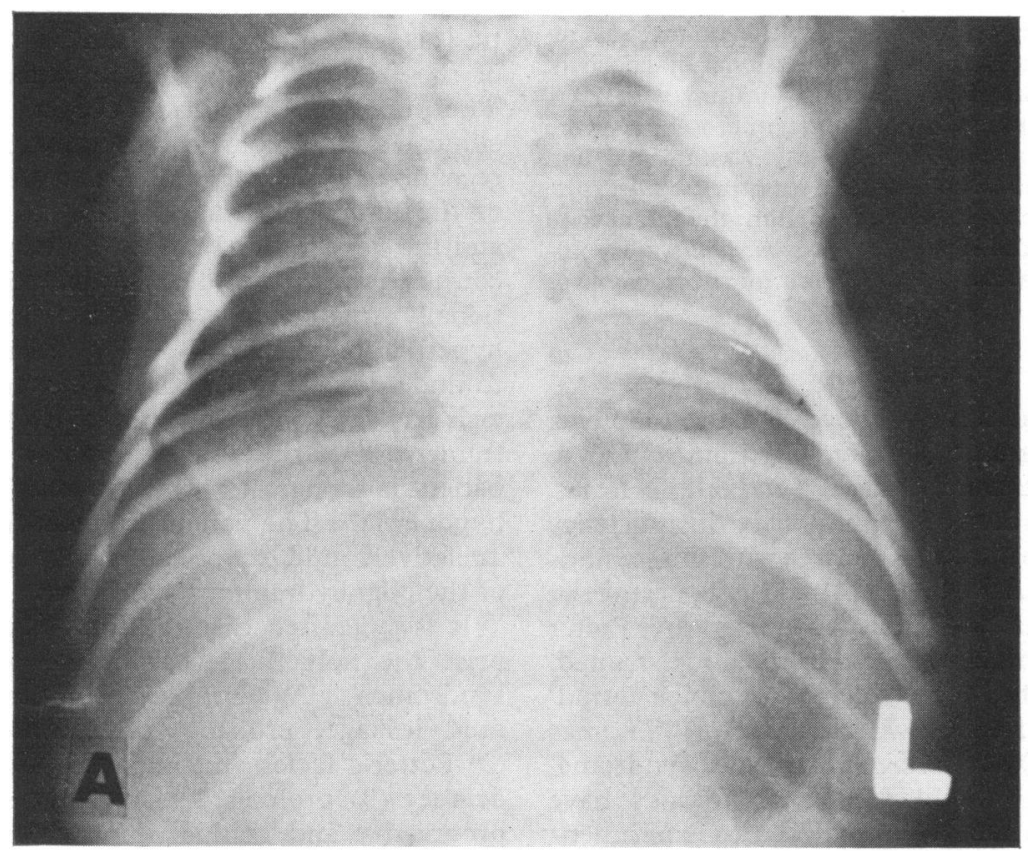

FIG. 2.-Case 3. Chest $x$-rays $(A)$ at 2 hours showing small thorax and minimal aeration of lung fields; $(B)$ at 3 days there was an increase in the transverse diameter of the thorax and improved aeration of both lungs. 
current enterocolitis at 7 weeks was followed by failure to thrive. At the age of 11 weeks the infant was readmitted to this hospital with a provisional diagnosis of septicaemia. White blood count $3700 / \mathrm{mm}^{3}$ with $23 \%$ neutrophils. Urine analysis and microscopy were negative, CSF normal. Chest $x$-ray was normal and there were no signs of pulmonary dysmaturity. In spite of intravenous gentamicin and penicillin, the infant died 12 hours after admission. Proteus mirabilis was cultured from the blood. Permission for necropsy was refused.

\section{Discussion}

The patients described above had the following features in common: (1) oligohydramnios due to chronic amniotic fluid leakage, (2) Potter's facies, (3) limb malpositions, (4) pulmonary insufficiency (Table). Fetal anuria is associated with similar firdings (Perlman and Levin, 1974) and concurrence of these phenomena was first recognized by Potter (1946) after whom the syndrome was named. More recently the terms 'oligohydramnios tetrad' (which includes fetal growth retardation) (Thomas and Smith, 1974) and 'oliogokydramnios syndrome' have been used. Similar external findings have been observed in rat fetuses exposed to experimental oligohydramnios (Poswillo, 1956; Kendrick and Feild, 1967; DeMeyer and Baird, 1969).

Cases 1 and 2 represent the oligohydramnios syndrome due to amniotic fluid leakage, a condition described by pathologists (Blanc et al., 1962; Bain et al., 1964; Kohler et al., 1970) but often not recognized during life by clinicians. In their series of 20 cases, Bain et al. (1964) noted that amniotic fluid leakage had continued for more than 3 weeks and that death occurred within 18 hours of delivery in all instances.
Case 3 differed both in the duration of the amniotic leakage (16 days only), and in the lesser degree of the features of the oligohydramnios syndrome. The pulmonary manifestations in this infant, both clinical and radiological, do not conform to any recognized disease entity. The gradual expansion of the lungs, evident clinically and radiologically, and the very gradual fall in the respiratory rate are consistent with the idea of anatomically and functionally small lungs at birth with compensatory hyperplasia postnatally. The ability of the lung to undergo rapid hyperplasia in response to atelectasis has been shown (Simnett, 1974). Seen in the framework of the oligohydramnios syndrome, this patient is thought to have suffered from pulmonary hypoolasia. The patient is considered to represent a relatively mild example in a bypothetical spectrum of the oligohydramnios syndrome.

It is suggested that the following featur 's comprise the nonlethal form of the oligohydramnios syndrome. (1) Chronic or subacute amniotic fluid leakage, probably of 2-3 weeks' duration; (2) Potter's facies and limb malpositions of minor degree; (3) prolonged respiratory symptoms with progressive and gradual improvement postnatally; (4) absence of diagnostic radiological findings apart from small lungs and a bell-shaped chest; and (5) a tendency to air-block syndrome (Liberman, Abraham, and France, 1969). Establishment of diagnostic criteria of pulmonary hypoplasia in living infants awaits further clinical and radiological discriptions.

In an infant born after prolonged amniotic fluid leakage and in whom resuscitative measures appear to be unsuccessful the diagnosis of pulmonary hypoplasia is facilitated by the observation of Potter's facies and limb malpositions. In addition,

TABLE

Associations of oligohydramnios in fetal anuria and amniotic fiuid leakage

\begin{tabular}{|c|c|c|c|c|}
\hline & $\begin{array}{c}\text { Fetal } \\
\text { anuria }\end{array}$ & $\begin{array}{c}\text { Experimental } \\
\text { amniotic } \\
\text { fluid leak }\end{array}$ & $\begin{array}{c}\text { Chronic } \\
\text { amniotic } \\
\text { fluid leak } \\
\text { (Cases } 1 \& 2 \text { ) }\end{array}$ & $\begin{array}{c}\text { Subacute } \\
\text { amniotic } \\
\text { fluid leak } \\
\text { (Case 3) }\end{array}$ \\
\hline $\begin{array}{l}\text { Potter's facies } \\
\text { Limb malposition } \\
\text { Pulmonary hypoplasia } \\
\text { Low lung weight: body weight } \\
\text { ratio } \\
\text { Reduced radial } \\
\text { alveolar count } \\
\text { Early neonatal death due to } \\
\text { respiratory failure } \\
\text { Tendency to alveolar rupture } \\
\text { Amnion nodosum }\end{array}$ & $\begin{array}{l}+ \\
+ \\
+ \\
+ \\
+\end{array}$ & $\begin{array}{l}+ \\
+ \\
0 \\
0 \\
0 \\
0 \\
0\end{array}$ & $\begin{array}{l}+ \\
+ \\
+ \\
+ \\
+\end{array}$ & $\begin{array}{c}0 \\
0 \\
- \\
0 \\
0\end{array}$ \\
\hline
\end{tabular}

+ , Usually present; -, absent; 0 , not known. 
the erroneous post-mortem diagnosis of pulmonary atelectasis can be avoided by drawing the attention of the pathologist to the external findings and by computing the lung veight: body weight ratio and radial alveolar counts, which are the criteria presently used for pulmonary hypoplasia (R:ale and Esterly, 1973).

The clinical implication for the obstetrician is that chronic amniotic fluid leakage should not be permitted to continue in the presence of oligohydramnios for more than 2 weeks. The recent suggestions of nonintervention in pregnancies of less than 32 weeks complicated by early membrane rupture (Scott, 1974; Reid and Christian, 1974) may lead to an increased incidence of the oligohydramnios syndrome. There are no published data indicating the frequency of this complication of chronic amniotic fluid leakage, but our own limited experience ( $P$ rlman, 1975) indicates that the oligohydramnios syndrome is very frequent in this situation.

The pathogenesis of hypoplastic lungs in oligohydramnios is unclear. Conditions such as intrathoracic space-occupying lesions (Reale and Esterly, 1973) or thoracic skeletal anomalies (Finegold et al., 1971) cause retardation of lung growth. Oligohydramnios may act by restricting the fetal thorax, or by altering the dynamics of lung fluid so as to cause a failure of the maintenance of expansion of the fetal lungs (Perlman, Levin, and Ben-Aderet, 1972; Thomas and Smith, 1974). Whatever the mechanism, the observations recorded reinforce the idea that a normal volume of amnotic fluid is a prerequisite for normal fetal lung development (Perlman and Levin, 1974).

\section{REFERENCES}

Bain, A. D., Smith, I. I., and Gauld, I. K. (1964). Newborn after prolonged leakage of liquor amnii. British Medical fournal, 2, 598 .

Blanc, W. A., Apperson, J. W., and McNally, J. (1962). Pathology of the newborn and of the placenta in oligohydramnios. Bulletin of the Sloane Hospital for Women, 8, 51 .
DeMeyer, W., and Baird, I. (1969). Mortality and skeletal malformations from amniocentesis and oligohydramnios in rats, cleft palate, clubfoot, microstomia, adactyly. Teratology, 2, 33.

Emery, J. L, and Mithal, A. (1960). The number of alveoli in the terminal respiratory unit of man during late intrauterine life and childhood. Archives of Disease in Childhood, 35, 544.

Finegold, M. J., Katzew, H., Genieser, N. B., and Becker, M. H. (1971). Lung structure in thoracic dystrophy. American Fournal of Diseases of Children, 122, 153.

Kendrick, F. J., and Feild, L. E. (1967). Congenital anomalies induced in normal and adrenalectomized rats by amniocentesis. Anatomical Record, 159, 353.

Kohler, H. G., Peel, K. R., and Hoar, R. A. (1970). Extramembraneous pregnancy and amniorrhoea. Fournal of Obstetrics and Gynaecology of the British Commonwealth, 77, 809.

Liberman, M. M., Abraham, J. M., and France, N. E. (1969). Association between pneumomediastinum and renal anomalies. Archives of Disease in Childhood, 44, 471.

Perlman, M. (1975). More on the 'oligohydramnios syndrome'. Fournal of Pediatrics, 86, 481.

Perlman, M., and Levin, M. (1974). Fetal pulmonary hypoplasia, anuria, and oligohydramnios: clinicopathological observations and review of the literature. American fournal of Obstetrics and Gynecology, 118, 1119.

Perlman, M., Levin, M., and Ben-Aderet, N. (1972). Renal malformations, oligohydramnios and pulmonary hypoplasia. Proceedings of the Fifth Israeli Congress Obstetrics and Gyneco$\log y$, p. 30 (Abstr.).

Poswillo, D. (1966). Observations of fetal posture and causal mechanisms of congenital deformity of palate, mandible, and limbs. Fournal of Dental Research, 45, 584.

Potter, E. L. (1946). Bilateral renal agenesis. Fournal of Pediatrics, $29,68$.

Potter, E. L. (1961). Pathology of the Fetus and the Infant, 2nd ed., p. 301. Yearbook Medical Publishers, Chicago.

Reale, F. R., and Esterly, J. R. (1973). Pulmonary hypoplasia: a morphometric study of the lungs of infants with diaphragmatic hernia, anencephaly, and renal malformations. Pediatrics, 51, 91.

Reid, D. E., and Christian, C. D. (1974). (Editors.) Controversy in Obstetrics and Gynecology, p. 55. (Editorial comment.) Saunders, Philadelphia.

Scott, W. C. (1974). Treatment of patients with premature rupture of membranes: a) prior to 32 weeks, b) after 32 weeks. Controversy in Obstetrics and Gynecology, p. 35 . Ed. by D. E. Reid and C. D. Christian. Saunders, Philadelphia.

Simnett, J. D. (1974). Stimulation of cell division following unilateral collapse of the lung. Anatomical Record, 180, 681.

Thomas, I. T., and Smith, D. W. (1974). Oligohydramnios, cause of the non-renal features of Potters' syndrome, including pulmonary hypoplasia. Fournal of Pediatrics, 84, 811.

Correspondence to Dr. M. Perlman, Neonatal Unit, Hadassah University Hospital, P.O. Box 499, Jerusalem, Israel. 